\title{
Rating the outcomes of psychotherapy using the Change After Psychotherapy (CHAP) scales. Manual and Commentary*
}

\author{
Rolf Sandell ${ }^{1 凶}$
}

\begin{abstract}
In what follows we shall describe the model for rating a kind of psychotherapy change that has been developed at the Institute of Psychotherapy in Stockholm. It has been inspired by American studies with follow-up interviews after psychoanalysis by Pfeffer (1959) and Schlessinger and Robbins (1974), among others. The model has two parts, one (or more) interviews and a set of ratings on the basis of this or these interviews. The interviews are basically focused on the patient's subjective experience of the state of having changed-or not. The patients are encouraged to tell about the way they feel now, compared to what they used to feel, and how their situation in life is at present, compared to what it used to be, and how their life has changed since they began or terminated therapy. The interviews are quite informal, unstructured from the point of view of the patient, roughly as in a therapeutic session, but they are also different in the sense that the interview has a defined focus and that there is also an interviewing guide, on paper or in the interviewer's mind. It is also possible to use regular therapy sessions, on tape or in the form of process notes or similar documents, for the same purpose of rating the experience of change. The method may not only be used for research or more formal evaluation; it may also be important for the therapist once in a while systematically to judge for himself/herself how a therapy is developing. Reliability, norms and psychometric properties are reported.
\end{abstract}

Keywords: psychotherapy outcome research, post-treatment evaluation, quantitative research, qualitative research

\section{Change and its measurement}

There is a curious paradox in the traditional way of measuring psychotherapeutic change by the difference between a patient's pre- and post-treatment scores. When initially a patient asks for a psychotherapy, claiming that s/he suffers, is unhappy, etc., researchers seldom doubt that this could be true, rather taking the patient's statements for granted. However, the same researchers typically would not rely on the patient's statements about his/her improvement due to therapy, although they might

\footnotetext{
${ }^{1}$ Department of Behavioural Sciences and Learning, Linköping University (Sweden); Department of Psychology, Lund University (Sweden)

Corresponding author: Rolf Sandell, Sandhamnsgatan 39, 11528 Stockholm, Sweden; email to: rolf.sandell@psy.lu.se
}

have expected that at the end of his/her psychotherapy the patient would have gained even more of introspective self-awareness than before. So why, in our role of researchers, should we adopt these double standards?

There are even more important problems related to measurement of psychotherapy outcome. The

\footnotetext{
* The CHAP scales were originally published in four articles that appeared in issue no. 1/1987 of the journal Psychotherapy and Psychosomatics (Sandell, 1987a, 1987b, 1987c, $1987 \mathrm{~d})$, while a manual, with a commentary, was written in 1997 in the form of a manuscript. The version of the manual published here has been slightly modified and updated by Paolo Migone together with Rolf Sandell. An Italian version of the CHAP - translated by Paolo Migone, Francesca Tondi, and Stefano Tempestini - appears in issue no. 4/2015 of the journal Psicoterapia e Scienze Umane (see web page www.psicoterapiaescienzeumane.it/chap.htm).
} 
traditional way of measuring change is to apply a measuring device to an object before some kind of treatment, an intervention or an event, and again apply the same device to the same object after the treatment and then calculate the difference between the two readings on the measuring device (Sandell, 1987a). This is based upon the idea that change is to move along a continuum which is qualitatively the same after the treatment as it was before. Another way to put this is that if the measured value is the same after the treatment as the measured value before, the two identical values have the same meaning (Lord, 1967). According to the same logic, different values represent a purely quantitative change on a single dimension of meaning. There are few things as disputable in psychological measurement theory -and few things have been discussed so much- as this way of measuring change (Harris, 1967). The discussion has mainly been about making the difference between the postmeasurement and the premeasurement independent of the premeasurement, that is the person's baseline, and how reliability attenuation could be avoided (Bereiter, 1967).

But to measure quantitative change is not only disputable from a mensurational point of view but also from a substantial point of view. The critical assumption is that whatever it is that one wishes to measure after the intervention is qualitatively the same as whatever it was that one measured before. It is built upon the premise that learning and other kinds of change comes about through quantitative steps of progress or regress of qualitatively the same kinds of knowledge and abilities and corresponding functions. A convenient model for this is building a wall by adding layers of identical bricks to eachother. But when one is learning things or when one is changing in other ways, it is more often the case that the change is qualitative. One changes by being or doing something in some other way than before, not by being or doing whatever it was one was doing more or less than before. It is true that one may find or invent quantitative aspects of this kind of change, for example, that something is being done more speedily or more accurately after an intervention than before, but the important point about viewing learning the qualitative way is that the new ability is constituted differently, is structured or organized differently. This is a very important difference between the quantitative and the qualitative way of regarding change, that the function that has changed is not more but different. In everyday life there are lots of examples that may serve as a model, for instance when you redecorate your home, when you change your clothes or buy new ones, or when you are rewriting a text.

It is exactly because of this "differentness" rather than "moreness" that the quality of change is not so easy to quantify when psychotherapeutic change is concerned. True, level of functioning is a quantita- tive concept, and so is severity of disturbance or symptoms, hence also changes in these respects. When personality change is concerned it is different, though. The really relevant parameter is "radicalness," meaning that qualitative change may be more or less radical, extensive, or thorough. If you redecorate a room by moving a chair, it is certainly less radical a change than if you move all pieces of furniture around. If you reorganize all paragraphs in a text, it is certainly more radical than if you move only one. So, how radical a change has a person undergone and how may this be quantified, in a loose sense or in a more exact way? There is a rather concrete criterion for such a kind of change that is quantifiable, at least in the subjective sense, like all kinds of sensory or perceptual experiences are, and that is to what extent the observer does not recognize himself or herself, maybe becomes surprised or astonished, impressed or disappointed, proud or frustrated, or whatever it is that one becomes when one stands before someone who has changed for the better or the worse. This last also implies that whatever degree of surprise that one experiences may be valued in a positive or negative way. Alternatively, in the case of no change, one may become bored or impatient or irritated or whatever, when one recognizes that everything is exactly as it was before, feels a kind of disappointment in one's hopes for a change, distrust and hopelessness because of the lack of change. It is not only the independent observer that may feel this way, also the subject, the person who is changing or is not changing as the case may be, may have such feelings in relation to his/her own change or lack of change.

Again as a model, when we go out in the street with a new set of clothes, who does not try to look at himself or herself in the shop windows, feeling different, sometimes embarrassed, sometimes proud, but in any case changed some way. This experience one might call, a bit awkwardly, the experience of the state of having changed, in order to emphasize that it is not about the change itself but about the consequences of it on the experiential level.

This is an experience that some patients have while in psychotherapy or after. One may feel more or less different than before, for instance when one realizes that the way one is doing or feeling now has not been done or felt that way before or when one realizes that one cannot understand how one could do or feel the way one did before. In a way one is feeling a kind of strangeness or alienation in relation to the person one used to be. One may feel surprised, glad, proud, curious before one's new way of being and thinking. Simply, one has a more or less new image of oneself. This is an essential feeling, because feeling different than before is so important an aspect of one's present, new self image. As part of one's new self image and, above all, as an agent of the change of the self image, the psycho- 
therapy and its consequences obtain an important role in the revision or rewriting of one's history which more and more scholars are regarding as the essential process in many psychotherapies.

\section{The follow-up interview}

In what follows we shall describe the model for rating this kind of change that has been developed at the Institute of Psychotherapy in Stockholm. It has been inspired by American studies with follow-up interviews after psychoanalysis by Pfeffer (1959) and Schlessinger and Robbins (1974), among others. The model has two parts, one (or more) interviews and a set of ratings on the basis of this or these interviews. The interviews are basically focused on the patient's subjective experience of the state of having changed-or not. The patients are encouraged to tell about the way they feel now, compared to what they used to feel, and how their situation in life is at present, compared to what it used to be, and how their life has changed since they began or terminated therapy. They are asked about the benefits that they feel they have had from their therapies; in what ways they now directly feel they have changed during or after the therapy; if and how they have noticed that other people have noticed that they have changed; and what events and what conditions external to the therapy that may have contributed to this; what they remember were particularly important events during therapy etc. The interviews are quite informal, unstructured from the point of view of the patient, roughly as in a therapeutic session, but they are also different in the sense that the interview has a defined focus and that there is also an interviewing guide, on paper or in the interviewer's mind. It is also possible to use regular therapy sessions, on tape or in the form of process notes or similar documents, for the same purpose of rating the experience of change. The method may not only be used for research or more formal evaluation; it may also be important for the therapist once in a while systematically to judge for himself/herself how a therapy is developing. In case one is doing special follow-up interviews, about one hour is usually enough to obtain rather complete information. The amount of time is partly a matter of one's own feeling, as an interviewer, of having reached an understanding or of wanting to reach something deeper. It is not infrequent, however, that one may feel that one has a clear picture already after half an hour or so. However, because the interview is often grasped by the patient as an opportunity to work through and systematically structure his or her therapeutic experiences, often for the first time at the conscious or verbal level, it is advisable to let the patient go on until one has the feeling that he or she has reached some kind of closure.

The follow-up interviews are free or informal in- terviews. As a rule, the interviewer should be a licensed, experienced psychotherapist. An unstructured and non-directive stance is what will prove most fertile, not least because that is what expatients have been used to in their therapies and therefore often expect or at least readily adjust to. This technical stance will give the interviewer an ideaalthough not an exact replica-of what the patient may have been like in his or her therapy, which may come useful as material in the interview or in evaluating the interview. So the interview proceeds superficially like a session in therapy, that is, with the patient as the most active part. For natural reasons, however, there is more direction from the part of the interviewer than from a therapist, particularly in the beginning, in order to convey the purpose and direction of the interview.

Thus, interviewing a patient like this, although superficially similar to a therapy session, is yet something quite different. Although it may be tempting for a therapist to act therapeutically, the purpose of an interview of course is to obtain information, not to facilitate further change. It is essential in a short time to produce a well-functioning interview alliance. Nevertheless, the interviewer should take a neutral, nonevaluative attitude and abstain from gratifying the patient by flattery, consolation, ingratiating sympathy or understanding. Certainly, the interviewer must not take a critical or even an indifferent attitude. A civilized, friendly, mildly supportive stance, without being enthusiastic or overly friendly etc., is recommended. Cooperation and alliance in the interview is based on a sincere and serious interest on the interviewer's part for what the patient may tell about his or her experiences, and he or she should only be encouraged to be as open and candid as possible in the interview. Thus, although one should be supportive and encouraging about the interview work itself, one should abstain from support or encouragement in extra-interview matters.

There is a specific countertransference trap to beware of in this connection. Some or many expatients may feel resistant and unwilling to share their precious time with a project which they may not regard as in their primary interest, at least to begin with. It may also require considerable time, effort, and flexibility to get in contact with them and find a space in the agendas that will suit both parties-or possibly will suit the expatient better than the interviewer. Further, it may so happen that the expatient brings residual negative transference or realistically negative critique and disappointment to the interview. These factors may, unconsciously, provoke in the interviewer aggressiveness, or defenses against aggressiveness in the form of an ingratiating attitude, sham understanding or acceptance, preventing in turn the interviewer from confronting the patient when this might have been appropriate, requesting clarifications, specifications, explanations and so forth. 
All possible interventions should be evaluated only in relation to the interest of the interview qua interview. Confrontations may be used to begin a clarification of contradictions or vague or confusing information. Various kinds of resistance in the interview, which by definition hampers the interviewing process, should also be addressed by confrontation, such as when the interviewer feels that the patient is obviously appeasing or resistant, inordinately afraid, suspicious, confusing, unfriendly or overly nice, amusing, humorous, ingratiating, companionate etc., not as a general trait but specifically in the interview situation. In the interest of gaining information, clarifications are frequently called for, in the form of questions, summaries, conclusions, requests for the patient's own interpretations etc. Interpretations should be generally abstained from, unless in a very general or loose sense, for instance, in the form of tentative summaries of what the patient seems to the interviewer to have been saying. One particular instance of another kind when an interpretation may be called for is when the patient seems to revive and re-enact the therapeutic or analytic transference. In connection with a remark that this seems to be happening (e.g., "I have the impression now that you may be believing that I am the same kind of person as your analyst-maybe that you even believe I am him/her"), the interviewer may take the opportunity to introduce the topic of the patient's present image of his or her therapist or analyst. Another case for an interpretation is when a confrontation to dissolve interview transference resistance, that is, transference that appears to arise afresh in the interview, rather than being revived, does not succeed. The patient then seems exaggeratedly and uncritically positive, flattering or placating, or supercritically negative, hostile, or suspicious, to the interviewer. Idealizations, deva-luations, denials, disavowals, projections etc. in the patient's account of the therapy should be accepted as they are and left with that, not confronted or interpreted, only clarified if necessary. The interviewer should always keep in mind that it is the understanding of the present experience of the patient or the expatient that is the project, not to enlarge or deepen his or her understanding or experience.

The interviewer should avoid conveying to the patient that he or she understands more than he or she actually does and avoid phrases like "Yes, I understand", "Yes, I see", when they are only used to try to increase a feeling of rapport and alliance. The usual " $\mathrm{Hmm}$ " is often sufficient, especially since that is what expatients are used to hear from psychotherapists anyway. Really, an attitude of mildly naive or even stupid non-understanding is more often appropriate in order to make the patient explain himself or herself more clearly. With the same purpose, the interviewer should never stay content with abstract, general statements about various kinds of change, but constantly ask for concrete examples or illustrations in terms of specific events or incidents. In what specific concrete ways does the patient experiences having changed, should be the leitmotif. It is a common kind of resistance on patients' part to be systematically vague, evasive or stereotypical, for instance, in sweeping and general accounts of specific events, with focus on what is general or typical, with jargon etc. If the patient says that he or she has gotten into better contact with his or her feelings, has gained insight in his or her patterns of relations or behavior, or thinks he or she functions better now than before, it is absolutely necessary for the interviewer to try to make the patient be more specific. Simple questions will generally do, like "What specific feelings?" "What patterns?" "What functions?" Patients using concepts like separation anxiety, paranoid, fixation etc. should be asked specifically what those words really mean to them.

An expectant attitude on the part of the interviewer is advantageous, that is, an attitude where the interviewer does not himself or herself bring up personal matters (e.g., familial, vocational, or sexual matters, problems, symptoms) or thera-peutic matters (e.g., the therapist as a person, the termination, disappointments) that are pertinent or of interest unless or until he or she feels convinced that the patient will not do so himself or herself. Thus, for example, the presenting problems of the patient at intake should not be brought up on the interviewer's initiative before the patient has had ample time to introduce such matters himself or herself. The possibility that the patient may no longer think actively about his or her presenting problems is important information, to begin with. The present status of the problems or the present severity of the symptoms are certainly as important but could be inordinately focused on by the interviewer if the patient is not himself or herself as focused on them any more. Negative experiences, like disappointment, hopelessness, and unfulfilled expectations are as important as positive experiences of relief, satisfaction, and joy, but possible feelings of either kind should not be asked for until the interviewer feels certain that the patient will not bring them up himself or herself. Thus, as a general principle, the funneling technique will be appropriate, where the interview starts the interview in an unfocused, nondirective way and gradually increases his or her direction or focusing only as much as is necessary for the patient to share the relevant information. As little prompting as possible is the ideal.

A number of set questions should be in the interviewer's mind. They can be put in any order in the interview as the process unfolds and should not be put at all if the patient provides the information on his or her own. The usual opening should be phrased some- 
thing like this:

"I am interested to hear about your experiences and present feelings about your psychotherapy; how your life has changed since you were in therapy, if and how you yourself have changed as a person, what benefits of different kinds you feel you have had of your therapy and what losses, what your expectations were and how they were fulfilled and what unexpected gains or losses you have experienced."

This somewhat lengthy introduction has as its purpose to instruct and direct the patient to the kind of information that is called for. Usually, patients who are experienced with dynamic psychotherapy will then take over the initiative and go on on their own. Sometimes, they may ask, "Where should I start?", or something of that sort. The interviewer then says, "It's your choice" and takes note of the patient's reaction.

When the interviewer feels that he or she will be able to answer the introductory questions-and a few more- on behalf of the patient, the interview is complete; if not, the interviewer should put the questions explicitly. Thus:

- in what ways, if any, have the patient's life situation and way of living changed during and after his or her therapy?

- in what ways, if any, has the patient himself or herself changed as a person during and after therapy?

- in what ways, if any, has the patient noticed that other significant persons (spouse, children, parents, friends, colleagues and workmates etc.) perceive or experience the patient differently than before?

- in what ways, if any, does the patient feel that the therapy has affected her life course, what benefits and what losses has the therapy brought about?

- what were his or her expectations before therapy and to what extent have these been fulfilled?

- what unexpected consequences, good or bad, has he or she been able to derive from the therapy?

- how does he or she now feel about the problems that originally made him or her seek psychotherapy; to what extent are they now solved, to what extent not?

- in the patient's opinion, what events or processes or conditions in therapy have contributed most to the positive outcomes of therapy and to the negative ones?

- what important events, outside therapy, have happened in the patient's life during and af- ter therapy, particularly such events that he or she believes may have contributed to the positive and the negative changes during and after therapy?

- what are the patient's present image of, and feelings about, the therapist, as a professional and as a person?

The interview should not be terminated until the interviewer recognizes that the patient himself or herself is ready to terminate. As a way of introducing the termination of the interview, the interviewer should make a summarizing statement of the main points that he or she feels have been made about the therapy, partly as a way of checking that he or she has grasped the essence of the patient's experience, partly as a signal that the interview is coming to a close. Of course, if the patient does not recognize the summary, the interviewer has to try to rectify what has been misunderstood or not completely understood, by introducing a second round of interviewing, now focusing on what seems to be missing in his or her understanding.

When the interviewer and the patient finally has come to an agreement and a mutual satisfaction or understanding, and when the interviewer feels convinced that the patient is ready to terminate, the interviewer should bring the interview itself into focus, by asking the patient how he or she has felt being interviewed and talking about the therapy. Possible questions about the purpose of the interviewing and the further processing of the interview might be addressed. The interviewer should conclude by expressing his or her gratitude to and appreciation of the patient for sharing his or her experiences and by stating the value of them for the benefit of the project.

\section{The rating procedure}

After the interview, the recording of it is then listened to and a set of ratings are made on the basis of a manual which is called CHange After Psychotherapy, CHAP (Sandell, 1987b). The task is for the rater to judge to what extent the expatient experiences himself or herself as having changed as a person in different ways. The issue is the experience of having changed. It should be kept in mind, then, that this experience has many facets and dimensions, some of which may be conscious, some preconscious, and some unconscious, and that these facets may not be totally consistent with each other. The question is, then, how much and in what ways he/she now feels different than before, consciously and unconsciously. Therefore, the rating is not merely a matter of 
transforming to a set of ratings what the patient has manifestly said but also a matter of inferring and interpreting the latent meaning that has been conveyed in all kinds of ways by the patient, even if only by not having been said. As a consequence of the kind of change being rated, viz., the present experience of having changed, a pretherapy interview or pretherapy ratings are not called for and may possibly even direct the rater away from the task at hand, by directing him or her to a comparison between his or her pretherapy and posttherapy impressions. It is another, empirical question to what extent the kind of change in question is in agreement with other kinds of change, like pre-to-post differences in symptoms or general adaptation, independent judges' opinions on change (rated benefits), or the evaluations of significant others. Accordingly, also, as much as agreement is not necessarily validating, differences are not invalidating, instead rather contributing to a richer picture of the complex outcomes of psychotherapy. For convenience, in what follows in this manual, we shall use the simple word change $(-d)$ to refer to that particular aspect which has been described as having the experience of being in a state of having changed.

The rating instrument is based upon a content analysis of interviews made with brief psychotherapy expatients at the psychiatric clinic at the Danderyd Hospital outside Stockholm. What the patients were telling there, when they were to describe the benefits or losses of the therapies they had been in and how they had changed during these therapies, could be subsumed under five categories or in terms of five rating variables. These variables are extensively-but not exhaustively-defined in the manual with the help of concrete examples of what patients do or may tell during follow-up interviews. In what follows, I shall give a general description of the rating variables and of various difficulties and aspects to be aware of in the rating task.

\section{Rating instructions}

The previously published rating manual (Sandell, $1987 \mathrm{~b})$ is given here in a slightly revised form.

The manifest signs of psychotherapeutic change, direct or interpreted, may differ in importance, scope, depth, and other dimensions, just as the change of the individual patient may be more or less radical, general, deep, thorough-going, worked-through etc. Without keeping track of each specific sign, it is assumed that the extent of qualitative change is proportional to the joint function of the number, importance, scope, and depth of the signs exhibited by the patient. It is also assumed that the rater may intuitively experience this joint function and transform it in- to a rating on a linear, that is, interval scale. Psychotherapy may bring about changes of many different kinds. In the following pages, you will find descriptions of change in the following four respects: symptom prevalence and tolerance; adaptive capacity; self-insight; and basic conflicts. On the basis of what you have heard and seen of the patient, or about him, after his therapy (and possibly before), you shall try to judge how much he or she has changed in each respect during and after therapy. Each variable is defined by a number of "signs," examples of what patients may show or tell as indicative of this particular aspect of change.

First read and consider carefully the definitions of the four variables. Remember that the lists of signs that define them are not exhaustive but merely examples to help you feel and understand what each variable is meant to mean. As you will see, each kind of change may be noticed in many different ways, some directly by the patient exhibiting them or credibly telling about them, some obvious and some less so, some important and decisive, some not so much so. Also, one and the same sign may indicate change in more than one aspect, in more than one of the rating variables. Although there may be a single decisive sign of change, in general, the greater the number and the importance of the signs exhibited by the patient, the greater and the more obvious should you consider the change.

Also remember that change is not necessarily quantitative, that one has more or less of some quality one had less or more of before. Rather it is often qualitative, in the form of new capacities, new habits, new insights, new ways to see of feel about oneself and others, and new ways to behave and talk. The only relevant quantitative aspects of such change is how radical or thorough-going it is, how much the new qualities differ from the old ones.

First make a rough rating of the amount of change on each variable according to the following scale:

\section{Great and/or obvious change 1 \\ Some and/or less obvious change $\quad 0.5$ \\ No and/or nonobvious change 0}

Then try to adjust your rough rating by making finer gradations between $1,0.5$, and 0 . This is rather more simple if you have several patients to rate on the same occasion-or if you can recall other patients that you have rated on previous occasions. Now, if there are patients who are on the same rough level of change, but you still feel that they have not 
changed to exactly the same degree, you should try to adjust your ratings so as to differ in roughly the same proportion as the patients differ in amount of change.

The rater should keep in mind that "great" or "some" should be taken in an absolute sense, if that is possible. Thus, the rating scores should not be assigned in relation to what might have been expected, considering the circumstances, adjusting for the conditions etc. This would make any comparisons impossible between different conditions or circumstances. A rater who would assume that brief therapy cannot be expected to bring about very much change might feel that slight change is great, whereas an equally slight change after a long-term psychoherapy would be considered small. Likewise, a rater might believe that a severely disturbed patient cannot change as much as a less disturbed patient and therefore tend to consider equal change as "great" in the former case but only "some" in the latter. This should be avoided. Thus, the rater should strive to adopt the same standard whatever the kind of therapy and whatever the kind of patient. To the extent that blind-folding is possible, considering that it is usually difficult or even impossible to conceal critical information in the interview, it is desirable.

Also, the meaning of a " 1 " rating may have to be explained. First, considering that it is indeed change that is being rated, the rater should beware of rating the patient's present state of functioning. Thus, a still low-functioning patient should be given a higher rating than a well-functioning patient if he or she has indeed changed more. So, a "1" rating should not be thought of in terms of very high present level of functioning. Keeping in mind that change is what is being rated, a "1" rating does not mean some kind of utopian change, one that is achievable only in principle. It should indeed be possible for patients to have a " 1 " rating if very radical change in the aspect being rated is described and/or inferred. For instance, a complete elimination of formerly severe symptoms should be rated "1", likewise a patient who may still have some symptoms left but is not at all concerned with them anymore and has learned to endure them, maybe even taking advantage of them, for instance by using anxiety as a signal. A formerly shy and timid person who is now self-confident and assertive may likewise be given a " 1 " in adaptive capacity. A person who did not previously realize that he or she had any inner life at all, being emotionally shallow and psychologically naive, may be rated a " 1 " if she or he now is able to see and understand herself or himself and other persons in terms of mental states and reflect on them. As was noted in the introduction, feelings of surprise, amazement and the like on the part of the person himself or herself or on the part of some observer are indicative of the extent of change and could be used to gauge the ratings.

\section{Symptom change}

Symptoms are those specific, manifest, and observable signs of some alleged illness that causes the patient to suffer and eventually seek therapy in order to get rid of them: anxiety, depressive feelings, phobic fears, obsessive thoughts or compulsive acts, and different kinds of somatic complaints. Now rate to what extent the patient's $(\mathrm{P})$ symptoms have been mitigated or to what extent $P$ suffers less from his/her symptoms. Such changes may be signified in the following ways, among others:

Symptoms have decreased in number, frequency, duration, severity, strength

$\mathrm{P}$ is less disturbed by his or her symptoms, e.g., less afraid of his/her anxiety, or can stand it better

P does not care about his or her symptoms

$\mathrm{P}$ does not talk spontaneously about his or her symptoms at all

P talks about his or her symptoms in the past tense

P considers his or her symptoms unimportant, nothing to talk about

P makes his or her symptoms a trifle

$\mathrm{P}$ looks upon his or her symptoms in a more objective way, with more emotional distance, $\mathrm{cu}-$ riosity, wonder, humor, trying to question and analyze them, reflect upon them

$\mathrm{P}$ does not consider himself or herself as much a passive victim of the symptoms

$P$ realizes that his or her symptoms were meaningful and functional, e.g., in terms of primary or secondary gains

P thinks he or she has "been cured"

$\mathrm{P}$ has not sought continued therapy or any other kind of treatment for his or her symptoms

$\mathrm{P}$ has learned to live with his or her symptoms

There are two aspects of symptomatic change, prevalence and tolerance. One is whether the symptoms have changed in terms of number, frequency, severity, strength, or duration. The second is whether the patient himself or herself now experiences her/his symptoms in another way than before, for instance if the person is now less or more troubled by them or is less or more concerned about them than before. Some examples: the patient directly tells that she/he has less symptoms now than before; the patient is talking about her/his symptoms in the past tense; the patient does not view himself/herself as much as before as a passive victim of his/her symptoms; the patient realizes that the symptoms are functional and meaningful, or the pa- 
tient does not talk about his/her symptoms at all except until asked about them.

There are a few specific complications with this variable. What is a symptom, to begin with? In a psychotherapy or psychiatric clinic this is fairly obvious, because most patients come to the clinic with manifest expressions of suffering of rather classical kinds, like anxiety, depression, traditional neurotic symptoms like phobias or obsessions, as well as somatic complaints that may be psychogenic. In CHAP we also regard potentially harmful acting-out and repetitive impulsive behavior as symptoms, especially when they have been taken as signaling that the patient is in need of treatment. But in psychotherapy it is often more complicated than that. Patients are usually seeking therapy for "problems." For instance, they may feel that they are not functioning so well in life, in relations, on the job, or in their studies as they would wish to, or they are suffering from a chronically bad selfconfidence or from a negative self-image, from guilt feelings, from various kinds of inhibitions, social, sexual, or vocational, from lack of spontaneity in their feelings or in their behavior, and so forth. It may not feel natural for all to call these kinds of phenomena symptoms. As a general working definition for CHAP ratings, symptoms should be regarded as all kinds of fairly circumscribed but transsituational or generalized behaviors that have produced some degree of suffering or concern in the patient or in his or her social environment (family, friends, workmates etc.).

Although, in most cases, it is fairly obvious what kind of suffering the patient initially sought therapy for, the therapeutic effect may sometimes be quite complicated to rate. An illuminating case is the following. Before therapy, a female artist had complained about her painful depression. In a follow-up interview she tells the interviewer that she still has a very deep depressive feeling most of the time and sometimes may feel hopelessly down, contemplating suicide. However, she is now beginning to be able to anticipate and recognize her symptoms when they start to appear, and she does not become as surprised or as terrified of them as she used to. The feelings are as deep and as painful as before, everything becomes stark black, but she has realized that they are part of life's conditions and that there is nothing to do about these. She has decided to go on living, and she has started to regard her depressive attacks as a kind of asset in her creative work that she previously did not have, simply by accepting them. She is not afraid of them anymore. Obviously, there has not been any noticeable amelioration of her symptom. On the other hand, there is considerable change in her experiencing her symptom, that is, in its subjective quality, that has led to increased tolerance of the symptom and less suffering. But it is more than that. Her depressive attacks are not only endured better than before but have turned from a deadly threat to a human and artistically creative asset without producing as much fear in the patient. Simple or, as in this case, more complex change in symptom tolerance-or, more generally, how the meaning and valence of the symptoms have changed-is one aspect that is badly covered by most conventional symptom questionnaires. Nevertheless, these and similar qualitative changes in the meaning of symptoms are quite frequent consequences of psychoanalytically oriented therapies and are also among their primary goals in principle. It is therefore incumbent on the interviewer and the rater to take specific note of such aspects, not confining themselves to simplistic modes of thinking about symptoms.

In the typical case, the patient himself or herself will spontaneously bring his or her presenting symptoms into the interview, sooner or later. However, in some cases, symptomatic improvement will evidence itself simply by the fact that the patient does not do so. Unless the interviewer, or the rater, knows what the presenting symptoms were at the beginning of therapy, such improvement will go unnoticed. It is therefore essential for the interviewer, or at least for the rater, to know what symptoms or problems the patient presented with initially, either on the basis of file charts or pretherapy interviews. On the other hand, it should also be kept in mind that some symptoms may have been concealed in the beginning, on purpose or not, or at any rate may not have been mentioned in the initial interviews or in the patient file. Therefore, it now and then happens that the patient mentions symptoms that the interviewer or the rater did not know of before. This should be clarified in the interview: Were they present initially, in what form and with what frequency and severity, why were they not mentioned then, when did they start etc.? The possibility of symptom substitution should also be kept in mind, that symptoms may be present at follow-up which were not there before but have superseded previous ones. As it is always a matter of judgment whether a symptom has really been substituted by a new one, such processes should be addressed and clarified, so that the interviewer and the rater may have at least some general idea of their interrelation. Of course, completely new symptoms may have emerged without any obvious relation to previous ones. Negative change is then indicated and should be balanced against possible positive changes in the rating.

\section{Adaptive capacity}

Adaptive capacity is the ability to handle such situations where previously symptoms appeared or when P used to become symptomatic, anxious, inhibited, or used to cope inadequately or nonadaptively ("critical situ- 
ations"). Signs of increased adaptive capacity are, among others:

P does not avoid or escape from critical situations anymore

$\mathrm{P}$ does not become anxious in or before critical situations

$\mathrm{P}$ relates concrete situations where he/she has acted more adequately than before, e.g., more assertively, flexibly, non-aggressively

$P$ exhibits obvious surprise, amazement, etc. while telling how he has acted in critical situations

$\mathrm{P}$ tells about changes in habits, ways of living etc., indicating that he or she is determined to do something about his or her problems

$P$ is proud and content with himself, that he/she may now manage things he/she did not manage before (without having symptoms)

P says he/she has decided to get rid of his/her symptoms and other problems

$P$ talks of himself or herself in relation to problems and symptoms as an active party, the one who rules and makes the decisions

$\mathrm{P}$ dares to do things he/she did not dare to do before

$\mathrm{P}$ is able to do things he/she could not do before

$\mathrm{P}$ makes a distinction between before therapy and after, between the way he/she used to be before therapy and the way he/she is now

$P$ has new interests and hobbies

$P$ has got new friends

$\mathrm{P}$ has now another job, either through promotion or change of function or through entering a completely new profession that he/she may have aspired on before

$P$ has started on a new line of training

P tells about old dreams that he or she has realized or started to realize

P may now do things he/she could only fantasize about doing before

$\mathrm{P}$ has loosened himself/herself from situations that were inhibiting, delimiting, destructive, e.g., jobs, marriage or other relations

$\mathrm{P}$ feels more autonomous, that is, more independent and willful, not at the mercy of circumstances, feels free to make his or her own decisions independent of the requests or wishes of his/her environment-but not independent of, or negligent of, its needs

$\mathrm{P}$ feels due responsibility for things that happen to him or her

$\mathrm{P}$ has freed himself from the compulsion to repeat old mistakes, place himself or herself in the same old problematic situations again and again

Adaptive capacity refers to how the patient is coping with or mastering external situations of some more or less specific kind that she/he has previously considered especially problematic or critical, for instance in so far as they have been connected to or provoked symptoms. Whereas the symptom rating refers to more or less circumscribed behaviors which the patient may experience as merely "happening" and which have caused the patient suffering, adaptive capacity refers to more or less specific situations which have been difficult to master or cope with and therefore have been troublesome to the patient, typically by eliciting symptoms. We call such situations "critical situations." Again, it is important to bear in mind that what is to be judged or rated is change in that aspect, as experienced by the patient. Increased adaptive capacity means better to be able to cope adaptively with such situations where symptoms used to "happen" to the patient or where he or she previously did not function adequately.

Note, here, that what should be required for a positive rating is some kind of truly adaptive resolution of the critical situation, not, for instance, a phobic escape from the situation that may well mitigate a symptom like anxiety-although that should yield a positive rating of symptom change. Decreased such adaptive capacity, in the patient's experience of himself or herself, will yield a negative rating.

Positive change will show itself, for instance, when the patient tells that she/he does not longer avoid situations that previously were anxietyprovoking; that she/he now acts more adequately and adaptively than he or she used to in such situations; that the patient describes herself/himself as more active and more autonomous in relation to her/his problems, to the external circumstances, or to what she/he has previously experienced as external forces or external restrictions. No particular kind of behavior is a priori more adaptive than others, of course. A previously competitive or overassertive person may have become more adaptive by being less competitive or assertive, and a previously inhibited and timid person may have become more adaptive by being more competitive or assertive. Change in adaptive capacity is also indicated when the patient is now talking about beneficial or stimulating changes in his/her out-door life, new friends, new relations, new interests, previous wishes that now have become reality etc.

In the rating of adaptive capacity there are sometimes complications that are not easily resolved. Again, a common difficulty is the case were there is a substantial symptom amelioration which has come about, and is maintained, by a phobic solution. A typical example is the elevator phobic who is not suffering anymore from his phobia because he always takes the stairs instead. Another example of this kind is the woman who frequently found herself in troublesome relations with men, where she would be let down and humiliated. She now no lon- 
ger has any problems of this kind-because she has now decided to abstain completely from any relations with men. She may have solved her problems, but hardly in a way that would be called adaptive, rather through avoidance and denial. Such ways to solve one's problems, again, may lead to high ratings of symptom change, because the symptoms are after all not as pressing as before, but it should also lead to low or even negative ratings of change in adaptive capacity, because the solution is not really adaptive in the long run or in a broader context.

Another kind of complication is not as easily resolved. An example of this is a woman with a traumatic background and upbringing, with several early separations where she was left by her mother; this happened, for instance, when her sister was born. In her first follow-up interview, six months after termination, she told that she had had intense and emotionally violent arguments or fights with her mother and sister, scolded them, pounding her anger at them etc. Without doubt, this should be considered as a kind of acting-out, but it is not obvious that, in a therapeutic process-or, as in this case, a posttherapeutic process-this is completely nonadaptive as a kind of working-through or reorientation, considering the history of the patient. This is, of course, on the condition that this repeated acting-out is finally remitting. For natural reasons this is difficult to decide in an interview when the acting-out is still going on, and this should lead to the decision to postpone the final rating until one is able to see how this acting-out process is developing.

The fact that nothing is forever, whether actingout or more unquestionably good solutions, is one very important reason why repeated follow-up interviews should be undertaken. The so-called effect of therapy is not a constant but can-and often does-vary fairly much during a couple of years. Here is an example: A man with a very strong inhibition of aggression during his first interviews told about some reasonably positive changes in this respect, most notably on his job, where he could be more assertive and unconciliatory. But in relation to his parents, who were after all the original targets of his aggression, his inhibition prevailed on the manifest level, although he could feel himself boiling within when he was talking to them. In the third interview, which was $2 \frac{1}{2}$ years after therapy termination, his maladaptive inhibitory defenses had broken down. On new years eve, for the first time he had started a fight with his parents, gotten furious, had had to much liquor, and then left to drive back to his own home. Unfortunately-for him, he ran into the police and was caught for drunken driver behavior. This is of course not adaptive in the short run, but how adaptive was his outburst towards his parents in the long run? A fourth interview, after still another year, revealed much anxiety and remorse in retrospect over this incident, but his outburst seemed to have had the adaptive consequence of familiarizing himself with, and increasing his tolerance with, arguments and quarrels. The previously pentup aggression towards his parents had subsided and consequently also his inhibitions, and he presented himself as an emotionally well-balanced persons, with somewhat diplomatic but still creative ways of coping with, rather than avoiding, interpersonal conflicts generally.

Ratings of change in adaptive capacity sometimes are heavily founded on the personal opinions and values of the rater, and this is unavoidably in the nature of the phenomenon. This will, however, sometimes lead to complications. Here is an example: A female patient told that, after her divorce, she had left her children in the care of their father. In order to judge the adaptive value of this fairly unusual decision on the part of a mother, one has to keep the entire picture of the woman in mind, with a fairly disturbed personality and a rather insecure social situation, in which her child might possibly become victimized, and one also has to try to neglect one's own ideas and ideals about what mothers should or should not do with the children.

\section{Self-insight}

Increased self-insight is a matter of understanding, better than before, and not only intellectually or in principle, one's problems, their background and etiology and their meaning. Signs of increased self-insight may be:

P says he/she realizes and understands the background and meaning of his/her problems

$\mathrm{P}$ may give a meaningful and reasonable account for the background and meaning of his/her problems

$\mathrm{P}$ talks about, and exhibits, feelings that he/she did not have access to before

$\mathrm{P}$ is more tolerant and understanding talking about his or her problems

$P$ has developed a split between and observing and understanding ego and an experiencing, feeling, fantasizing, and wishing ego

$\mathrm{P}$ is aware of instances of acting-out and can describe them as such

$\mathrm{P}$ is aware of transference phenomena and repetition compulsions and can describe them as such

P may see and take his or her share of responsibility in interpersonal conflicts

$\mathrm{P}$ is reasonably "suspicious" about his own feelings, thoughts, and acts, that is, does not take them for granted without wondering about their meaning

$P$ may see and talk about his or her own defenses and resistances 
P has discovered previously ego-syntonic symptoms and symptomatic habits

$\mathrm{P}$ has become aware of, and begun to tolerate, aspects of himself/herself that he/she was not aware of before, e.g., wishes and fantasies

$P$ feels more ambivalent about situations and other people and can stand it without actingout

$\mathrm{P}$ feels disillusioned but considers it a gain as well as a loss

P feels more curious about himself/herself, muses and reflects more on himself/herself

$\mathrm{P}$ is not equally prone to blame others for his own problems, difficulties, and shortcomings

$P$ may criticize himself or herself in a more objective and less accusing way

$\mathrm{P}$ may talk about his/her problems and difficulties with more emotional distance and selfirony or humor

$\mathrm{P}$ ponders over his/her dreams and tries to understand them

$P$ ponders over parapraxes and tries to understand them

$\mathrm{P}$ is better able to predict own and others' feelings, reactions and actions

$\mathrm{P}$ has sought another, lengthier or insightoriented therapy

$\mathrm{P}$ may see primary and secondary gains with his or her symptoms

$P$ talks less about his or her symptoms than about the underlying problems

An excellent source of further examples and illustrations of what is here called self-insight is now being developed by Fonagy, Steele, Steele, Target and Schachter (April, 1996) under the name of reflective-self functioning. The manual is still in limited circulation. Reflective self-functioning is the operationalization of a metacognitively monitoring function that appears to be a necessary precondition for the development of self-insight.

Make sure that self-insight is not only an intellectual skill but an intellectual and emotional phenomenon. The patient can show or tell about feelings that she/he did not previously have access to, or she/he can tell about a greater tolerance with and a greater understanding of her/his difficulties. She/he can exhibit a kind of split in an observing and an experiencing ego. She/he may be reasonably skeptical to, and suspicious-in a good sense-of, what he himself or she herself is feeling, thinking and doing. $\mathrm{He} /$ she can be objectively self-critical without being self-accusative etc.

When self-insight is concerned, there are several circumstances that make this a difficult variable to rate. For one thing, remember that what is being judged and rated are changes in this capacity, not its present level. It is difficult to know how much selfinsight there were to begin with and how much has been added, so to speak. As with the other variables, one has to try to ascertain the person's present experience of having changed. In this particular instance, however, it becomes a slightly paradoxical matter, because being able to tell one's present experience itself presupposes a certain extent of selfinsight. With some persons, on the other hand, experiencing having changed will simply reveal their lack of self-insight, because the change and the experience of it may be illusory. So the rating of selfinsight amounts very much to try to discern genuine from sham self-insight or mere superficial jargon.

This particular problem is closely related to the following circumstance. One reason why selfinsight is often difficult to rate is that many patients tend to be quite vague when they are speaking about their insights. It is rather typical for them to tell that they came to realize "a lot of things," that they came to view "things" differently than they did before, that they now regard themselves differently than they did before, that they now view themselves in a clearer light than before, that they have now uncovered and gotten rid of (parts of) their own self-deceptions etc. But when the interviewer starts asking specifically what it is that they are now viewing differently or knowing differently than before, there is often no clarifying response but mere repetition, an equally vague response or blunt avoidance. It then becomes more a matter of trust on the part of the interviewer, and he/she has to use his/her countertransference to differentiate genuine descriptions from clichés.

Vague descriptions, intellectual descriptions, clichés etc. in general should not yield high ratings in any of the variables. On the other hand, it may be in the nature of insight that what has been repressed returns, surfaces so to speak, becomes restructured, is given a new meaning and a new feeling, is discharged and then disappears in a more normal way, that is, not as repression to the unconscious but as "ordinary" forgetting in the preconscious. Therefore, the patient should be allowed time for recollection and reconstruction in the interview, and this very process will reveal much of value for the rating of this variable.

But it is not always so easy to judge changed selfinsight even when the patient is precise and concrete. An interesting case is the patient who, during her therapy, has come to the conclusion that she knows so very little about herself, knows herself so little. At the same time as there is a kind of deficit in selfinsight that is being noted, it is itself a kind of humble insight which may not be very frequent and which may be one aspect of what is sometimes called psychological-mindedness.

In this category we may also include the fairly large number of patients who have come to the conclusion after their therapies-particularly if these were short-term ones-that they need more therapy, 
longer and more intensive, in order to deepen their understanding of themselves. One has to judge this from case to case, of course, but this is one of the signs which we have started to note as a criterion of increased self-insight and which may be considered a good beginning of a long-term therapy or a psychoanalysis rather than a miscarried short-term therapy.

\section{Basic conflicts}

Resolution of a basic conflicts means that the basic conflict does no longer take priority over, or infiltrate, all tasks or situations in life. A basic conflict is the typically unconscious remnants of an early and largely unsolved conflict or a trauma. Conflicts may be thought of in terms of the traditional id - super-ego - ego schema or-in an objectrelations frame of reference-in terms of conflicting introjects; traumas in terms of loss, separation, deprivation, excessive gratification, under- or overstimulation, seduction, assault, threat, danger, illness, or injury. Under the influence of unresolved basic conflict, the person will act as if, in any situation, he cannot help returning to the conflict or trauma by finding, construing, or inventing the conflictual or the traumatic aspect, as if to repair a failure. An unresolved basic conflict will reveal itself as the consistent, sometimes compulsive, application of a rigid and preformed schema for the perceptions, cognitions, affects, acts, or reactions of the person. It acts like a filter through which the person perceives and reacts to persons or relations, events and situations, so as to emphasize some certain aspect. Examples of such aspects are, separation - symbiosis; chaos, annihilation - order, petrification; safety risk or chance; trust - distrust; sincerity - reserve; giving - receiving; deprivation; activity - passivity; masculinity - femininity; sexuality; aggressiveness; injury; destruction; power, dominance - powerlessness, submission; rivalry, competition, jealousy, envy; shame, exposure, ridicule; guilt, prohibition, decree; competence - incompetence; self-respect, self-esteem; identity.

A basic conflict may be described or implied in the therapeutic focus or issue, if one has been formulated, or in dynamic hypotheses, diagnoses, or case summaries or formulations. It should not be necessary, however, to have it defined beforehand in order to judge its resolution. In general, resolution of a basic conflict will be indicated by less rigidity and more flexibility, open-mindedness, less defensiveness, more spontaneity. Specifically, resolution of a basic conflict will signify itself in various ways, for instance:

P knows "what it is all about"

$P$ can give a meaningful and reasonable account of the basic conflict

Confrontation with the basic conflict provokes less anxiety or resistance

$\mathrm{P}$ is more flexible and open-minded in his/her attitudes and habits

$P$ is more tolerant towards others

$P$ has more empathy with others

$\mathrm{P}$ is able to see situations and problems from the points of view of others

$P$ is a better listener

$\mathrm{P}$ is not as rigid, stereotypical, extreme as he used to be

$P$ has abandoned previously vital routines and rituals

$\mathrm{P}$ is not as fond of his hobbyhorses anymore

P's habit of tuning in on always the same subject, often in the very same words as always, has weakened

P's character has modified or changed

$\mathrm{P}$ has given up characterological defenses

Other persons feel that $P$ has changed

$\mathrm{P}$ is not equally defensive, suspicious, on his/her guard

$P$ does not react as if on trigger-stimuli, automatically, reflex-like

$\mathrm{P}$ is not as easily provoked, does not as easily lose control

$\mathrm{P}$ is not as fond of, or prone to, categorical judgment

$\mathrm{P}$ seems to be developing, be in a state of continuous change, without being unstable or unpredictable

$P$ is not afraid of change, whether in himself/herself or in his/her environment

$\mathrm{P}$ is not afraid of taking reasonable risks, is not dependent on guaranteed outcomes

In rating this variable, it should be understood that a person is likely to have more than one conflict, maybe even more than one basic conflict, although it is probable that one is "basically basic" and the others more or less derivatives of that one.

Changes in the patient's basic conflict might be regarded as the essence of structural change, in the classical, albeit very loose, sense of psychoanalysis. Such change is a kind of reconstellation of all sorts of intrapersonal defenses, perceptual, cognitive, and behavioral, or interpersonal attitudes, acting-out tendencies or habits, to cope with own drives and impulses (in classical psychoanalytic theory) or with conflicts between one's introjects (in objectrelations theory). Such conflicts are about basic polarities as, for instance, separation vs. symbiosis, trust vs. distrust, chaos or annihilation vs. order or petrification, activity vs. passivity etc. A general 
description of how one may detect changes in these aspects would be that the patient has substituted flexible defenses for anxiously rigid defenses, which is expressing itself in increased openness and mental mobility This is what one might call adaptive structural change. It may show itself when the patient can offer material where he/she is now appearing, in different ways, as more open-minded, more tolerant, more empathic, less stereotypical, less extreme, less easily provoked, less suspicious, and less fearful of risks and changes.

To rate changes in basic conflicts, especially in retrospect, is certainly not uncomplicated. After all, it is a variable that is supposed to reflect the innermost and most concealed aspects of the change process, and this is not only difficult to see but also difficult to define, to begin with. Like self-insight, the person's awareness of it may also be subject to repression or forgetting after the therapy in a way which is not the case with symptoms and adaptive capacities. Another problem is also how, as observers, we are guided by our theoretical preconceptions, for instance about what is possible to achieve in a psychotherapy. It is probably rather difficult for some of us to believe that any deep-going structural change is possible in a brief therapy. Besides, one may have the idea that symptom change cannot occur without structural change, or that structural change cannot occur without insight and be accordingly influenced by such assumptions in one's ratings.

The psychoanalytic literature in general seems mostly to avoid the issue of explicating structural change and how it will show itself. Instead, one seems to prefer to follow more indirect paths, for instance by studying change in everyday functioning or adaptive capacity or other phenomena that are assumed not being able to manifest themselves unless a structural change has occurred (Zilberg, Wallerstein, DeWitt, Hartley \& Rosenberg, 1991). To focus on the dissolution of rigid defensive structures to the favor of more open, flexible and tolerant attitudes is, to our minds, closer to the core of what structural change should be taken to mean. Several formal procedures have been presented during the last decade to describe what appears to amount to very much the same phenomenon as what is called here a basic conflict, for instance, a coreconflictual relationship theme (CCRT; Luborsky \& Crits-Christoph, 1990), a plan (Weiss, Sampson \& the Mount Zion Psychotherapy Research Group, 1986), or a state of mind (Horowitz, 1991).

As in the case of increased self-insight, the rating of change in basic conflicts is of course complicated by the difficulty to rate the degree of change itself, independent of the level that has been achieved or of the pretherapy level. For instance, it is easy to fool oneself to rate a still low borderline type of level as in essence unchanged, although it may happen that, on closer inspection, one would realize that it has been a step upwards from a very low position. Conversely, there is the danger of rating the existence of flexible defenses at a high level as a large change, although they may have been at the same general level all the time. To get at the bottom of the complex of conflicts, some previous formulation in terms of plans, CCRTs or whatever may be helpful.

We believe that the best kind of material for judging conflict change is when the patient describes his or her relations, particularly his or her relations to primary objects like parents, and in what ways and to what extent she/he now considers these relations different, in particular when there is a more flexible and tolerant attitude toward the primary objects being described, especially in those aspects one had come to consider as particularly troublesome or conflictual on the basis of the pretherapy interviews. Encouraging the patient to talk about his/her introjects or inner presences (Schafer, 1986) in terms of inner critics, inner tempters or the like will often prove helpful.

\section{Extra-Therapeutic Factors}

To what extent do you think events and conditions outside therapy, during therapy or afterwards, may explain the changes that you may have recognized? Note that extra-therapeutic conditions do not really include such as are themselves the effects of therapy and themselves in turn cause or facilitate further change. Thus, it is only a matter of conditions which are independent of therapy, so far as may be discerned. It is, by the way, not unusual for patients to play down the contribution of their therapy-or exaggerate it. Examples of extra-therapeutic conditions are:

Time has passed, that is, $\mathrm{P}$ has "simply" improved as time as passed since termination

$\mathrm{P}$ has grown older, entered a new stage in his/her life cycle or has matured in "the natural way"

$\mathrm{P}$ has been through, and come out of, a normal process of crisis

$\mathrm{P}$ has had a healthy change of environment ("natural environmental therapy")

$\mathrm{P}$ has "simply" been working on himself, independent of the therapy

$\mathrm{P}$ has had other supportive, consultative, or insight-bringing non-psychotherapeutic or non-psychiatric contacts (friends, relatives, colleagues)

$\mathrm{P}$ has been in some other psychotherapy

$\mathrm{P}$ has been in psychopharmacological treatment

$P$ has had other kinds of psychiatric treatment

P has been somatically ill, had an accident, or suffered physically 
$P$ has suffered misfortune or been in other kinds of crises

Stressful environmental conditions have ceased

$P$ has withdrawn from a stressful and symptom-provoking situation

$P$ has been cured from somatic illness

$\mathrm{P}$ has become involved in religious, political, or other kinds of ideological movements

$P$ has fallen in love

$P$ has been under the influence of some catharctic authority

$\mathrm{P}$ has changed while in some relation posing as therapy ("pseudo-therapy")

Of course, it is impossible to determine exactly how large a share of change depends on the above and other extra-therapeutic conditions. Try to establish what conditions of that kind have existed and to judge to what extent they may have contributed to the various aspects of change that you have noticed. These ratings, preferably one for each of the change variables separately, are thus a matter of your conviction that change has been entirely due to therapy, or your doubts that it has. First, make a rough rating:

Change may be entirely extra-therapeutic

Change may be equally therapeutic and extra-therapeutic 0.5

Change may not at all be extra-therapeutic

If you feel it is desirable and possible, you may adjust your rating by finer gradations between the above values. You should then follow the same principle as in making your previous change ratings.

Change ratings may be corrected with respect to extra-therapeutic conditions by the formula

$$
\mathrm{TC}=\mathrm{C}(1-\mathrm{E})
$$

where TC is therapeutic change, $\mathrm{C}$ the change ratings, and $\mathrm{E}$ the rating of extra-therapeutic conditions.

The four variables that have been described before are variables of change. However, these kinds of changes may of course be due to other conditions than the psychotherapy the effect of which one is trying to rate. It is not unusual for patients to tell about events outside therapy which they consider have contributed substantially to the changes they are now experiencing. This may be expressed in fairly vague manners like, "It is difficult to tell whe- ther it is really the therapy that has brought this about," which of course should be taken to mean that the therapy is not completely integrated in the patients own experience of his/her change. The patient may also point to the passing of time, that he/she has become older etc. Some patients can tell about a healthy change of environment, a new love relation, or separation from a bad relation etc. New crises, illnesses, and accidents cannot be excepted as contributing to this kind of pseudotherapeutic effect.

To judge exactly how much change is extratherapeutic and how much is genuinely therapeutic, that is, due to the therapy the effect of which one is trying to judge at the moment-not to possible new therapies or other treatments-is of course impossible. This way to formulate the problem is putting unreasonable demands on the rater. The only thing one is able to judge for oneself is one's own feeling of certainty or one's own doubts that the changes observed are effects of the therapy.

Particularly obvious but also complicating are cases where there is a concurrent or later professional treatment of a formal kind, for instance psychiatric treatment, with talks and/or pharmaceutical treatment, new psychotherapy or psychoanalysis, courses, conferences etc. In relation to the therapy the effect of which one is rating, all other formal or informal treatments become Extra-Therapeutic Factors. It is even more difficult to judge the extratherapeutic contributions of lay therapy, suggestion, and other kinds of influences from important persons in the expatient's environment. One patient, for instance, felt that the therapy had been meaningless but that having been scolded by a cousin of hers had brought miracles about. It is not as frequent for patients to be in more than one individual therapy at the same time, but it is not uncommon for a patient to be in family therapy or couples therapy at the same time as in individual therapy. After therapy such kinds of therapy are fairly common. The following four examples are chosen at random from the archive of interviews.

Patient \#1: During her therapy she was in an administrative course that she herself describes as a shift of paradigms. Besides, she has been to a psychiatric emergency room in connection with the death of one of her friends. Besides, once a week, she has been in couples therapy and also, during the last month, she has been in some kind of body therapy together with her husband. Finally, she has a chronic somatic disease starting and has an ongoing regular somatic treatment contact on that account.

Patient \#2 tells that he has been in family therapy while in individual therapy at the institute and also says that he has now had time for thinking and reconsideration. 
Patient \#3 was left by her husband after the termination of therapy and for a while was in family counseling, then in an individual crisis therapy and then continued in a more regular long-term therapy with the same therapist.

Patient \#4 indeed has had no later form of therapy. However, she has started working with retarded people, which is now helping her to look at herself in a more distant perspective than she used to.

Several concurrent treatments is a problem which is probably more frequent in treatment evaluation than one is ready to believe, although it may not be as common for researchers to try to find out, because that would complicate their findings. However, it is even more complicated than it appears at first sight, because it is not always possible to exclude the possibility that these "extra-therapeutic therapies" really were themselves the effects of the first therapy. One may have that impression, for instance, when, some years after her brief therapy, the patient has started a long-term therapy because she had come to realize things that she wanted, but had not time, to resolve during the first, brief therapy.

\section{Reliabilities and norms}

After reading about all difficulties, problems, and complications in rating therapeutic change one may ask oneself whether it is ever possible to be able to produce sufficiently reliable ratings of therapeutic change (Sandell, 1987c).

In Table 1, the coefficients of agreement (ICCs) between independent raters in some recent studies at the Institute of Psychotherapy are presented. One is a study of 35 interviews after a series of brief therapies, the second study is based on 60 follow-up interviews with 38 patients, of which 20 had been in brief therapy and 18 in long-term therapies. The third study had two interviewers, both psychotherapists outside the Institute of Psychotherapy, rate a random sample of 33 interviews in the lastmentioned study. Their training was considerably less extensive than in the previous two studies. The first value in each cell is the agreement between the raw ratings of independent raters. The second value in each cell is the agreement in the rating of ExtraTherapeutic Factors in relation to the change variable. Finally, the bottom entries refer to the sum scale, which is simply the sum of the raw scores on each of the four change variables, and the corrected sum scale, where the raw scores are first is adjusted with respect to extra-therapeutic change ratings.

In general, inter-rater agreement tends to be satisfactorily high in the two left-most columns, lowest for self-insight and basic conflicts among the change variables. When Extra-Therapeutic Factors are concerned, adaptive capacity and, in one of the two studies, self-insight are lowest. The agreement between the external raters (in the right-most column) is, however, much lower and not satisfactory. There may be several reasons for this. The effect of less training is likely to be one; the raters at the Institute of Psychotherapy had had regular seminars for several years, whereas the external raters had only had two sessions of discussion. Another reason is probably that the culture at the Institute, most raters/therapists having more than 10 years of employment, was a strong common frame of reference. More important than any of these, however, is probably the fact that the external raters did not utilize the possible range of ratings as much as the interns did. As we shall see shortly, the variance in their ratings, across patients, was typically four to five times smaller than the variance in the interns' ratings of the same patients. Such relative lack of differentiation will attenuate reliability as a matter of course. It is important, therefore, for the rater to endeavor to spread his or her ratings as much as possible, not shunning " 1 " or " 0 " ratings when change may be considered great or very small or non-existent.

Obviously, judgments of change cannot ever be objective in any sense of the word and, therefore, neither can the ratings. Rating norms may nevertheless be interesting as a token of the frame of reference which has developed at the Institute of Psy-

Table 1. Coefficients of Agreement (ICC) Between Independent Raters

\begin{tabular}{lccc}
\hline & $\begin{array}{c}\text { Brief therapy study } \\
n=35\end{array}$ & $\begin{array}{c}\text { Follow-up study } \\
n=60\end{array}$ & \multicolumn{2}{c}{ External raters } \\
& .88 & .81 & .56 \\
\hline Symptoms & .76 & .76 & .47 \\
ETF $^{1}$ & .87 & .81 & .56 \\
Adaptive capacity & .73 & .71 & .37 \\
ETF & .62 & .74 & .60 \\
Self-insight & .77 & .63 & .44 \\
ETF & .80 & .75 & .41 \\
Basic conflicts & .90 & .80 & .51 \\
ETF & .87 & .83 & .65 \\
Sum scale & .86 & .83 & .65 \\
Corrected sum scale & 2 &
\end{tabular}

Note. ${ }^{1}$ ETF $=$ Extra-Therapeutic Factors. ${ }^{2}$ Corrected with respect to ETF ratings 
Table 2. Means (M) and Standard Deviations (SD) in Three Different Studies With CHAP

\begin{tabular}{|c|c|c|c|c|c|c|}
\hline & \multicolumn{2}{|c|}{$\begin{array}{l}\text { Brief therapy study } \\
\qquad n=35\end{array}$} & \multicolumn{2}{|c|}{$\begin{array}{l}\text { Follow-up study } \\
\qquad n=60\end{array}$} & \multicolumn{2}{|c|}{$\begin{array}{c}\text { External raters } \\
n=33\end{array}$} \\
\hline & $M$ & $S D$ & $M$ & $S D$ & $M$ & $S D$ \\
\hline Symptoms & 0.52 & 0.38 & 0.57 & 0.37 & 0.51 & 0.17 \\
\hline ETF $^{1}$ & 0.25 & 0.29 & 0.28 & 0.30 & 0.37 & 0.14 \\
\hline Adaptive capacity & 0.56 & 0.34 & 0.54 & 0.33 & 0.47 & 0.16 \\
\hline ETF & 0.26 & 0.30 & 0.25 & 0.28 & 0.38 & 0.14 \\
\hline Self-insight & 0.46 & 0.23 & 0.49 & 0.27 & 0.37 & 0.14 \\
\hline ETF & 0.14 & 0.25 & 0.20 & 0.27 & 0.33 & 0.15 \\
\hline Basic conflicts & 0.30 & 0.26 & 0.31 & 0.28 & 0.23 & 0.11 \\
\hline ETF & 0.11 & 0.24 & 0.11 & 0.24 & 0.27 & 0.17 \\
\hline Sum scale & 0.46 & 0.26 & 0.48 & 0.27 & 0.40 & 0.13 \\
\hline Corrected sum scale ${ }^{2}$ & 0.39 & 0.26 & 0.38 & 0.27 & 0.27 & 0.12 \\
\hline
\end{tabular}

Note. ${ }^{1}$ ETF $=$ Extra-Therapeutic Factors. ${ }^{2}$ Corrected with respect to ETF ratings

chotherapy. The means and standard deviations of the ratings are exhibited in Table 2 . That it is a fairly stable frame of reference is evident from the fact that the mean ratings and the standard deviations in the two studies are quite similar. In that frame of reference, ratings of symptom change and adaptive capacity tend to be highest and ratings of basic conflicts lowest. Obviously, also, the dispersion of the ratings across patients is quite large. In contrast, as previously noted, the spread of the ratings of the external raters is much smaller. Also, their mean ratings on the change variables tend to be between 0.05 and 0.1 lower than among the interns, whereas their ratings of Extra-Therapeutic Factors are considerably higher, between circa 0.1 and 0.2 . This in turn will produce much lower means on the corrected sum scale for the external raters than for the interns.

The correlations among the change variables tend to be quite large, between circa .5 and .8 , as may be seen in Table 3. A single factor is indicated, or two strongly correlated factors, one "outer" change (symptoms and adaptive capacity) and one "inner" change (self-insight and basic conflicts). That there are two factors is suggested by the simplex pattern of the correlations, in the series, symptoms - adaptive capacity - basic conflicts - self- insight, where the correlations are lower the longer the distance between two variables in the series. Also, the Extra-Therapeutic Factors, one rating for each change variable, tend to be strongly intercorrelated, between .45 and .75 . The change variables and the Extra-Therapeutic Factors are, in general, weakly and negatively correlated.

The strong correlations between the change variables and between the Extra-Therapeutic Factors may have at least two reasons. One is that therapeutic change, measured in $z$-scores, may be generalized, although the levels of change may differ between the variables. If so, the correlations reflect the nature of therapeutic change. The second possible reason is that raters generalize their ratings or, conversely, are unable to differentiate between the variables. In that case, this tendency should be counteracted.

\section{General comments and advice}

Some general problems in using CHAP will be touched upon in this section. There is a kind of conflict inherent in all kinds of evaluation. On the one side, one naturally wishes to be able to make a statement about the treatment as a type or category, whether it is very effective, not so effective or wha-

Table 3. Correlations Between the Rating Variables

\begin{tabular}{|c|c|c|c|c|c|c|c|}
\hline & \multicolumn{3}{|c|}{ Change variables } & \multicolumn{4}{|c|}{ Extra-Therapeutic Factors } \\
\hline & $\begin{array}{l}\text { Adaptive } \\
\text { capacity }\end{array}$ & Self-insight & $\begin{array}{c}\text { Basic } \\
\text { conflicts }\end{array}$ & Symptoms & $\begin{array}{l}\text { Adaptive } \\
\text { capacity }\end{array}$ & Self-insight & $\begin{array}{c}\text { Basic } \\
\text { conflicts }\end{array}$ \\
\hline \multicolumn{8}{|l|}{ Change } \\
\hline Symptoms & .81 & .47 & .59 & -.11 & -.22 & -.14 & .09 \\
\hline Adaptive capacity & & .55 & .70 & -.27 & -.28 & -.28 & -.05 \\
\hline Self-insight & & & .71 & -.18 & -.21 & -.04 & -.01 \\
\hline Basic conflicts & & & & -.25 & -.25 & -.15 & .01 \\
\hline \multicolumn{8}{|c|}{ Extra-Therapeutic Factors (ETF) } \\
\hline Symptoms & & & & & .77 & .46 & .47 \\
\hline Adaptive capacity & & & & & & .61 & .53 \\
\hline Self-insight & & & & & & & .73 \\
\hline
\end{tabular}


tever. Such a statement presupposes that there is a fairly general outcome that is typical and preferably common to the treated patients. The larger the variance, the less meaningful it is to make such statements. True, there is an average outcome but none general or typical. Probably, it is in the nature of psychotherapy and psychoanalysis that the effects vary across patients (Sandell, 1997). This will have several consequences. One is that, because true variance is information in a statistical sense, the reliability of an effect measure that captures this variance will be higher. Further, for the same reason, correlations with other variables-for instance, predictors-will be higher, hence more reliable. On the other hand, the larger the variance, the smaller the effect sizes and the smaller the probability of significant differences in relation to other treatments (Sandell, 1987d). As a consequence of this, there has arisen a trend to manualize therapies in order to reduce variance and have some measure of the effects of the ideal treatment of its kind. Thus, variance in therapy outcome is a dilemma, and it may be tempting for a therapist using CHAP to suppress it in his or her ratings. Insofar as the variation is true and therefore reliable, such a tendency is inadvisable. It is important for the user of any rating instrument to try to exploit the whole range of possible ratings and avoid any kind of centralizing tendency or clustering of the rating objects.

Another complication in the use of CHAP is the somewhat unusual model of change which is it's rationale. Raters have to fully appreciate and review this model and adopt it, if CHAP ratings are to be meaningful. Change in CHAP is the patient's conscious and unconscious experience of being in a state of having changed, not a movement from one level to another on some level-of-functioning variable. The quantitative parameter is "differentness", the experience of having changed more or less radically, often indicated by feelings of amazement and the like.

One complication in this is what freedom the interviewer or rater has to make judgments (and consequent ratings) which do not agree fully with those of the patient or expatient. It may be important to emphasize that the rater is allowed to make judgments different from those of the patient if these may be defended and substantiated in a meaningful way. Indeed, insofar as the observer may be aware of processes, fantasies, and ideas that are unconscious to the patient, his or her judgments should differ. The most common case is when the interviewer/rater has the feeling that the patient does not sound genuine, does not feel convincing, when one has the impression that what the patient is saying is rather some practiced jargon, when the patient may not support general statements by concrete instantiations, or when the patient seems to act out a manic or depressive defense. Often, there is not much else but the rater's feeling to indicate such cases, and, like any countertransference feelings, these have to be dealt with carefully before being accepted as indicating anything about the patient rather than about the interviewer. It should be stressed that such poses on the part of the patient may as often fool the rater to overvaluation as to undervaluation of the thera-peutic outcome. In any case, obviously, the experience of indeed having changed less or more, respectively, has not been consciously integrated by the patient. It may be reasonable to value conscious experiences higher than unconscious ones in making one's ratings, not least because the subjective well-being of the patient is an important palliative therapeutic goal. The interviewer, being also a therapist, may then feel tempted to interpret what the patient appears to be unaware of, particularly if it is a more positive image of the therapy than what the patient is aware of. Except, perhaps, for a very cautious trial interpretation-after all, the patient may indeed be aware of it-the interviewer should abstain from pressing his or her awareness on the patient, since this is an interview, not a therapy.

Nevertheless, follow-up interviews may have, and often do have, therapeutic effects of their own. A kind of pseudotherapeutic effect of doing follow-up interviews is that most patients value being interviewed very positively, according to our experiences at the Institute of Psychotherapy. Often it seems to be taken as an indication that the Institute-and possibly the therapist-still cares. As a possibly more important effect, the patient is offered, and may take, maybe for the first time, the opportunity to reflect upon, repeat, integrate, or solidify, what has happened in therapy, with the added advantage of the perspective that time passed will allow. It is also probably impossible for any interviewer to avoid making supportive or other kinds of therapeutic interventions, if only by structuring, making or pointing to connections, clarifying statements in order to become himself or herself clearer. One consequence of such interventions is that this may influence the rater to believe in more change than is actually the case; another is of course that they may influence the patient to present himself or herself in another way than he or she would have done without the interventions. A third consequence may become more obvious in the following interview, if there is one, when the patient has developed a positive transference on the interviewer and further change as an effect of the previous interview. In general, however, we have found, in an experimental test, that such carry-over effects between interviews are nonsignificant.

The training of interviewers and raters is a very important part of adopting CHAP for regular use. At the Institute of Psychotherapy, it is our experience that the discussion seminars are highly valued, not only, or primarily, for the sake of doing better interviews or ratings, but for the fact that they usu- 
ally offer so much food for thoughts about therapy and being a therapist. It is an important experience for therapists adhering to the same general school to realize how differently they may hear what is being said at the very same audiotape. Interpretations are different and evaluations even more so. All sorts of personal or idiosyncratic theories and values emerge. For instance, the mother who had left her children in their father's care provoked quite different ratings between female and male raters. Other cases may not be so obvious but demand-just because of their notso-obviousness-that interviewers and raters are thoroughly trained and continue their training after $\mathrm{CHAP}$ has been put in regular use.

There are probably no measurement instruments without problems, and subjective rating instruments, in particular, are full of them. CHAP is certainly no exception. On the basis of our long experience with CHAP as well as other rating methods, however, we feel confident in recommending it as a meaningful and potentially reliable source of knowledge about important aspects of change in psychotherapy and psychoanalysis. Good luck!

\section{References}

Bereiter, C. (1967). Some persisting dilemmas in the measurement of change. In: Harris, 1967, pp. 3-20.

Fonagy, P. \& Target, M. (1993-2000). Attaccamento e funzione riflessiva. Milano: Raffaello Cortina.

Fonagy, P., Gergely, G., Jurist, E.L. \& Target, M. (2002). Affect Regulation, Mentalization, and the Development of the Self. New York: Other Press (Italian translation: Regolazione affettiva, mentalizzazione e sviluppo del Sé. Milano: Raffaello Cortina, 2004).

Fonagy, P., Steele, M., Steele, H. \& Target, M. (1998). Reflective Functioning Manual, Version 5.0: For application to Adult Attachment Interviews. London: University College London. Internet: mentalizacion.com.ar/images/notas/Reflective \%20Functioning\%20Manual.pdf. Vedi Amadei, Tronconi \& Giustino, 1998.

Harris, C.W., editor (1967). Problems in Measuring Change. Madison, WI: University of Wisconsin Press.

Horowitz, M.J., editor (1991). Person Schemas and Maladaptive Interpersonal Patterns. Chicago, IL: University of Chicago Press.

Lord, F.M. (1967). Elementary models for measuring change. In: Harris, 1967, pp. 199-211.

Luborsky, L. \& Crits-Christoph, P. (1990). Understanding Transference: The CCRT Method. New York: Basic Books (Italian translation: Capire il transfert. Milano: Raffaello Cortina, 1992).
Luborsky, L. (1984). Principles of Psychoanalytic Psychotherapy. A Manual for Supportive-Expressive Treatment. New York: Basic Books (Italian translation: Principi di psicoterapia psicoanalitica. Manuale per il trattamento supportivo-espressivo. Torino: Bollati Boringhieri, 1989). Manuscript with copyright of 1976.

Pfeffer, A. (1959). A procedure for evaluating the results of psychoanalysis. Journal of the American Psychoanalytic Association, 7, (3), 418-444. doi: 10.1177/000306515900700302.

Sandell, R. (1987a). Assessing the effects of psychotherapy. I: Analysis and critique of present conventions of estimating change. Psychotherapy and Psychosomatics, 47, 1: 2936. doi: $10.1159 / 000287995$.

Sandell, R. (1987b). Assessing the effects of psychotherapy. II: A procedure for direct rating of psychotherapeutic change. Psychotherapy and Psychosomatics, 47, (1), 37-43. doi: 10.1159/000287996.

Sandell, R. (1987c). Assessing the effects of psychotherapy. III: Reliability and validity of "Change after Psychotherapy". Psychotherapy and Psychosomatics, 47, (1), 44-52. doi: $10.1159 / 000287997$.

Sandell, R. (1987d). Assessing the effects of psychotherapy. IV: The incompatibility between the logic of the experiment and the nature of psychotherapy. Psychotherapy and Psychosomatics, 47, (1), 53-58. doi: 10.1159/000287998.

Sandell, R. (1997). Psychotherapeutic change is predictable, spontaneous change is not. Journal of Clinical Psychology, 53, (8), 925-933.

Schafer, R. (1968). Aspects of Internalization. New York: International Universities Press.

Schlessinger, N. \& Robbins, F. (1974). Assessment and follow-up in psychoanalysis. Journal of the American Psychoanalytic Association, 22, (3), 542-567. doi: $10.1177 / 000306517402200305$.

Wallerstein, R.S. (1986). Forty-two Lives in Treatment: A Study of Psychoanalysis and Psychotherapy. New York: Guilford.

Weiss, J. (1993). How Psychotherapy Works. Process and Technique. New York: Guilford (Italian translation: Come funziona la psicoterapia. Preface by Paolo Migone \& Giovani Liotti. Torino: Bollati Boringhieri, 1999).

Weiss, J., Sampson, H. \& the Mount Zion Psychotherapy Research Group (1986). The Psychoanalytic Process: Theory, Clinical Observation, and Empirical Research. New York: Guilford (Italian translation of ch. 1: Weiss J., Introduzione al lavoro del "San Francisco Psychotherapy Research Group". Psicoterapia e Scienze Umane, 1993, XXVII, 2: 47-65).

Zilberg, N.J., Wallerstein R.S., DeWitt K.N., Hartley D. \& Rosenberg S.E. (1991). A conceptual analysis and strategy for assessing structural change. Psychoanalysis and Contemporary Thought, 14, (2), 317-342.

Submitted: September 2015

Accepted: October 2015

Published: December 2015 